mgr inz. Krzysztof Gtaz

Politechnika Poznańska

prof.dr hab.inz. Krzysztof Magnucki

Politechnika Poznańska,

Instytut Pojazdów Szynowych”TABOR”

\title{
Wyboczenie sprężyste płyt prostokątnych z otworami kołowymi
}

\begin{abstract}
Przedmiotem pracy sa plyty prostokatne z otworami kolowymi. Przeprowadzono badania numeryczne metodq elementów skończonych wyboczenia tych plyt. We wstęie, na podstawie literatury, opisano wyniki badań dotyczace konstrukcji cienkościennych z otworami, wykonane w ostatnich latach. W dalszej części pracy przedstawiono wyniki badań numerycznych, wskazano na wptyw średnicy otworu na wartość naprężeń krytycznych. Wyniki tych badań przedstawiono $w$ tablicach oraz na rysunkach. Analogicznie badania wykonano dla ptyt $z$ usztywnionymi brzegami otworów kołowych za pomoca opasek jedno- $i$ dwustronnych.
\end{abstract}

\section{Wprowadzenie}

Część maszyny, której jeden z wymiarów (grubość) jest zdecydowanie mniejszy od pozostałych uważana jest za cienkościenna. Konstrukcje cienkościenne są szeroko stosowane $\mathrm{z}$ uwagi na ich wysoką wytrzymałość i małą masę. Współczesne pojazdy transportu lądowego, morskiego i powietrznego są konstrukcjami cienkościennymi. Intensywny rozwój tych konstrukcji, zwłaszcza $\mathrm{w}$ aeronautyce i lotnictwie, był możliwy dzięki starannie formułowanej teorii płyt i powłok oraz metodom numerycznym. Zauważalne jest od wielu lat wprowadzanie wielu osiagnięć przemysłu np. lotniczego do innych konstrukcji transportu lądowego.

Teoria konstrukcji cienkościennych, problemy wytrzymałości i stateczności są rozwijane od ponad stu lat i opisane w wielu monografiach np. przez Timoshenke i Woynowsky'ego-Kriegera [14] lub Bazanta i Cedolina [1]. Problemy wyboczenia części konstrukcji cienkościennych z otworami są mało opisane w literaturze. Otwory w konstrukcjach są nieuniknione $\mathrm{z}$ powodów technologicznych lub eksploatacyjnych, są przyczyna spiętrzenia naprężeń. Shanmugam [12] szeroko opisał problematykę otworów, którą podzielił na cztery grupy: płyty z otworami, kołnierze wzmacniające, perforowane środniki belek, kształtowane na zimno części stalowe. Wpływ otworu na wytrzymałość zależy od jego kształtu, wielkości, rodzaju obciążenia, ich ilości i rozmieszczenia, wzmocnień. W poszczególnych przypadkach możliwe jest połączenie zmniejszenia masy konstrukcji $\mathrm{z}$ redukcją naprężeń zredukowanych $\mathrm{w}$ stosunku do elementów bez wycięć, lub uniknięcie dużego ich przyrostu.

Maiorana i inni [6] opisali stateczność płyt kwadratowych i prostokątnych $\mathrm{z}$ otworami kołowymi poddanych zginaniu i osiowemu ściskaniu w zakresie sprężystym. Wielkość otworu wpływa na naprężenia krytycz- ne, podobnie odchylenie jego położenia od głównej osi bezwładności płyty. W kolejnej publikacji tych autorów [10] opisano wyboczenie sprężyste i plastyczne płyty prostokątnej $\mathrm{z}$ otworami kołowymi i prostokątnymi, obciążonymi siłą tnąca. Pod uwagę wzięto takie parametry jak wielkość i typ otworu, jego umiejscowienie względem dwóch głównych osi, orientacja otworów prostokątnych, wiotkość. Autorzy zaobserwowali m.in. wzrost współczynnika wyboczenia tnącego (shear buckling coefficient) dla otworów kołowych umieszczonych w obszarze zbiegania się sił tnących, lepsze właściwości wytrzymałościowe wiotkich paneli z otworami prostokątnymi, ogólny spadek naprężeń krytycznych wraz ze zmianą proporcji długości do szerokości płyty, znaczący wpływ wymiarów otworu kwadratowego oraz mniejszy jego położenia względem głównej osi symetrii płyty na wyboczenie. Obszary uplastycznienia materiału powstałego $\mathrm{w}$ wyniku wyboczenia skupiają się wokoło otworu.

Wpływ pojedynczego lub wielu otworów w płytach prostokątnych poddanych zginaniu i ściskaniu w zakresie sprężystym był także przedmiotem badań Moen i Schafer [7]. Rozważyli oni dwa modele warunków brzegowych, typowych dla środnika (sztywne) oraz półki belki (niesztywne), a także dwa kształty wycięcia: prostokątne i okrągłe. El-Sawy i Nazmy [3] badali płyty prostokatne $\mathrm{z}$ otworami kołowymi oraz prostokątnymi $\mathrm{z}$ zaokrągleniami, umieszczonymi $\mathrm{w}$ różnych pozycjach względem głównych osi bezwładności płyty. Obliczenia MES w zakresie sprężystym wskazały konieczność unikania otworów kołowych w określonych strefach płyty, wykazały także wyższość otworów prostokątnych z zaokragleniami o dłuższym boku prostopadłym do długiego boku płyty nad wycięciami z dłuższym bokiem równoległym. El-Sawy i 
inni [4] za pomocą MES badali płyty kwadratowe oraz prostokatne (proporcje 2:1) z otworami kołowymi w zakresie sprężysto-plastycznym. Zauważyli spadek dopuszczalnych naprężeń zredukowanych wraz ze wzrostem wiotkości (wzrostu pocienienia) oraz wzrostem gabarytów otworów. Wyboczenie zależy w dużym stopniu od punktu utraty elastyczności, zwłaszcza dla grubszych płyt gdzie możliwe jest wyboczenie sprężysto plastyczne. El-sawy, i Martini [5] rozważyli także przypadek płyty prostokątnej z pojedynczym otworem kołowym poddanej jednocześnie ściskaniu wzdłuż osi x oraz ściskaniu/rozciaganiu wzdłuż osi y. Autorzy wskazali na szczególnie niekorzystny przypadek jednoczesnego ściskania $\mathrm{w}$ dwóch kierunkach zwłaszcza przy otworach o średnicy większej niż 0,4 szerokości płyty. Paik [8] zastosował MES do badania płyty prostokątnej w zakresie sprężysto-plastycznym z centralnie umieszczonym otworem kołowym poddanej obciążeniu tnącemu. Potwierdził spadek odporności na wyboczenie wraz ze wzrostem gabarytów otworu, wzrostem proporcji gabarytów płyty i pocienieniem płyty. Ten sam autor w kolejnej publikacji [9] rozważał płytę z centralnym otworem kołowym poddaną dwuosiowemu ściskaniu oraz obciążeniom tnącym. Podkreślona została zależność pomiędzy wyboczeniem plastycznym, sprężystym a grubością płyty.

Shimizu [13] zwrócił uwagę na problem wyboczenia materiału wokół wycięcia w strukturach poddanych jednoosiowemu rozciaganiu, w wyniku lokalnej koncentracji naprężeń ściskających zwłaszcza wokół otworów prostokątnych. Eccher, K. i inni [2] analizowali modele numeryczne kształtowanego na zimno profilu z różnego typu otworami za pomocą metody pasm skończonych. Wykazali jej przydatność i dokładność na podstawie porównania z metodą elementów skończonych, uzyskując dobrą reprezentację naprężeń i odkształceń przy stosunkowo niewielkiej ilości elementów skończonych. Prabhakare i Datta [11] badali płyty prostokątne $\mathrm{z}$ otworami obciążone dynamicznie; rozpatrywali zagadnienie częstotliwości drgań własnych i postaci wyboczenia w funkcji wymiarów otworów.

Przedstawiona powyżej literatura została zawężona tylko do problematyki otworów w jednorodnych płytach, stanowi tylko pewną część opublikowanych prac i nie wyczerpuje tego tematu. Kolejnym, coraz częściej poruszanym zagadnieniem są otwory $\mathrm{w}$ strukturach kompozytowych takich jak laminaty czy struktury wielowarstwowe. Zauważalna jest niestety niewielka liczba publikacji dotyczących otworów w konstrukcjach cienkościennych w języku polskim. Umiejętność prawidłowego projektowania otworów w elementach cienkościennych ma rosnące znaczenia $\mathrm{w}$ nowoczesnych konstrukcjach.

\section{Model MES płyty}

W systemie ABAQUS zamodelowana została płyta kwadratowa o boku $a=300 \mathrm{~mm}$ i grubości $t=2$ $\mathrm{mm}$. Warunki brzegowe przedstawione są na rysunku 1. Przyjmując za środek układu współrzędnych punkt przecięcia głównych osi bezwładności $(0,0)$ dla 4 krawędzi ograniczono przemieszczenie $\mathrm{W}$ osi $\mathrm{z}$ (UZ=0), punktów $(-150,0),(0,150)$ w osi y $(\mathrm{UY}=0)$, punktów $(0,150),(0,-150)$ w osi x $(U X=0)$. Płyta obciążona jest równomiernie rozłożonym obciążeniem ściskającym na krawędziach poziomych. Dla płyty bez otworu wykonano analizę wyboczenia w celu uzyskania punktu odniesienia dla dalszych obliczeń. Następnie wykonano serię obliczeń dla płyt z otworami kołowymi o średnicy d od 10 do $290 \mathrm{~mm}$ (z krokiem $10 \mathrm{~mm}$, wariant 0 ).

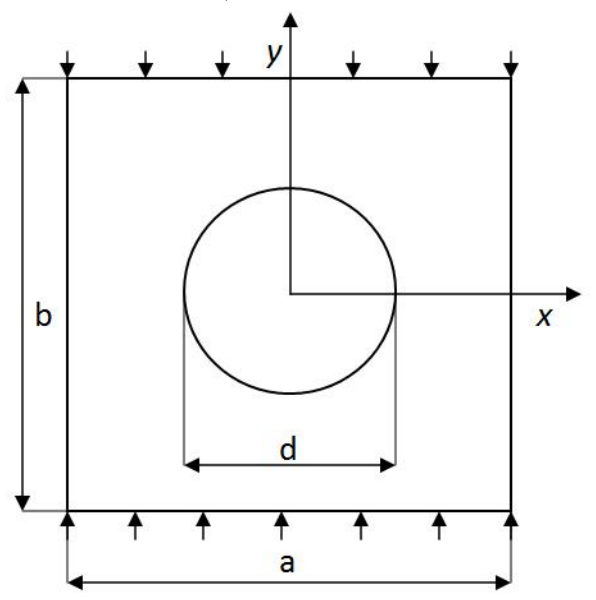

Rys. 1. Warunki brzegowe płyty

Kolejne serie obliczeń dotyczyły wyboczenia płyty $\mathrm{z}$ usztywnionym brzegiem otworu kołnierzem o następujących wymiarach:

wysokość 2,5 mm na każdą stronę (wariant A);

- wysokość $2,5 \mathrm{~mm}$ w kierunku $\mathrm{z}^{+}$(B);

- wysokość 2,5 mm w kierunku z- (C);

- wysokość $5 \mathrm{~mm}$ na każdą stronę (D);

- wysokość $5 \mathrm{~mm}$ w kierunku z+ (E);

- wysokość 5 mm w kierunku z- $(\mathrm{F})$.

Przyjęto następujące właściwości materiału: moduł Younga E=205 $\mathrm{MPa}$ oraz liczbę Poisson'a $v=0,3$. Element skończony odkształcalny typu Shell 3D, przyjęty eigensolver typu Subspace zwracający pięć pierwszych wartości własnych macierzy. W analizie danych każdorazowo wykorzystano pierwszą wartość eigenvalue.

\section{Obciążenia krytyczne i postacie wyboczenia plyty}

Wyniki uzyskane z postprocesora zestawione są $\mathrm{w}$ tabeli 1 oraz na wykresie 1 . 
Tabela 1

\begin{tabular}{|c|c|c|c|c|c|c|c|c|}
\hline \multicolumn{9}{|c|}{ WYNIKI KOŃCOWE DLA MODE 1} \\
\hline \multirow[b]{2}{*}{$\begin{array}{c}\mathbf{d} \\
{[\mathrm{mm}]}\end{array}$} & \multirow[b]{2}{*}{$\mathbf{d} / \mathbf{a}$} & Wersja 0 & Wersja A & Wersja B & Wersja C & Wersja D & Wersja E & Wersja F \\
\hline & & \multicolumn{7}{|c|}{ Naprężenia zredukowane von Misesa [MPa] } \\
\hline 0 & 0,00 & 32,08 & 32,08 & 32,08 & 32,08 & 32,08 & 32,08 & 32,08 \\
\hline 10 & 0,03 & 50,98 & 33,61 & 35,7 & 34,58 & 32,59 & 32,28 & 34,99 \\
\hline 20 & 0,07 & 56 & 33,42 & 38,2 & 40,52 & 40,42 & 33,11 & 37,57 \\
\hline 30 & 0,10 & 56,8 & 40,17 & 39,18 & 50,64 & 57,17 & 33,31 & 38,29 \\
\hline 40 & 0,13 & 55,77 & 46,22 & 40,09 & 59,94 & 60,78 & 33,55 & 38,61 \\
\hline 50 & 0,17 & 52,13 & 36,83 & 39,97 & 44,63 & 41,45 & 35,23 & 37,88 \\
\hline 60 & 0,20 & 51,95 & 39,72 & 41,13 & 46,48 & 43,76 & 41,24 & 38,82 \\
\hline 70 & 0,23 & 50,27 & 41,95 & 41,91 & 47,64 & 45,33 & 47,15 & 44,89 \\
\hline 80 & 0,27 & 49,02 & 43,68 & 42,9 & 48,36 & 46,44 & 52,89 & $\begin{array}{c}50,89 \\
\end{array}$ \\
\hline 90 & 0,30 & 47,13 & 44,83 & 45,28 & 48,63 & 46,99 & 59,93 & 65,18 \\
\hline 100 & 0,33 & 46,11 & 45,99 & 48,99 & 48,97 & 47,62 & 68,28 & 75,78 \\
\hline 110 & 0,37 & 45,98 & 46,91 & 58,9 & 49,15 & 48,13 & 73,34 & 77,91 \\
\hline 120 & 0,40 & 45,54 & 47,87 & 58,5 & 49,47 & 48,65 & 76,63 & 75,88 \\
\hline 130 & 0,43 & 44,65 & 48,84 & 47,19 & 49,85 & 49,17 & 62,39 & 57,01 \\
\hline 140 & 0,47 & 44,73 & 49,95 & 51,31 & 50,37 & 49,9 & 66,03 & 60,92 \\
\hline 150 & 0,50 & 45,47 & 51,31 & 56,04 & 51,2 & 50,89 & 69,88 & 65,03 \\
\hline
\end{tabular}

Wykres 1

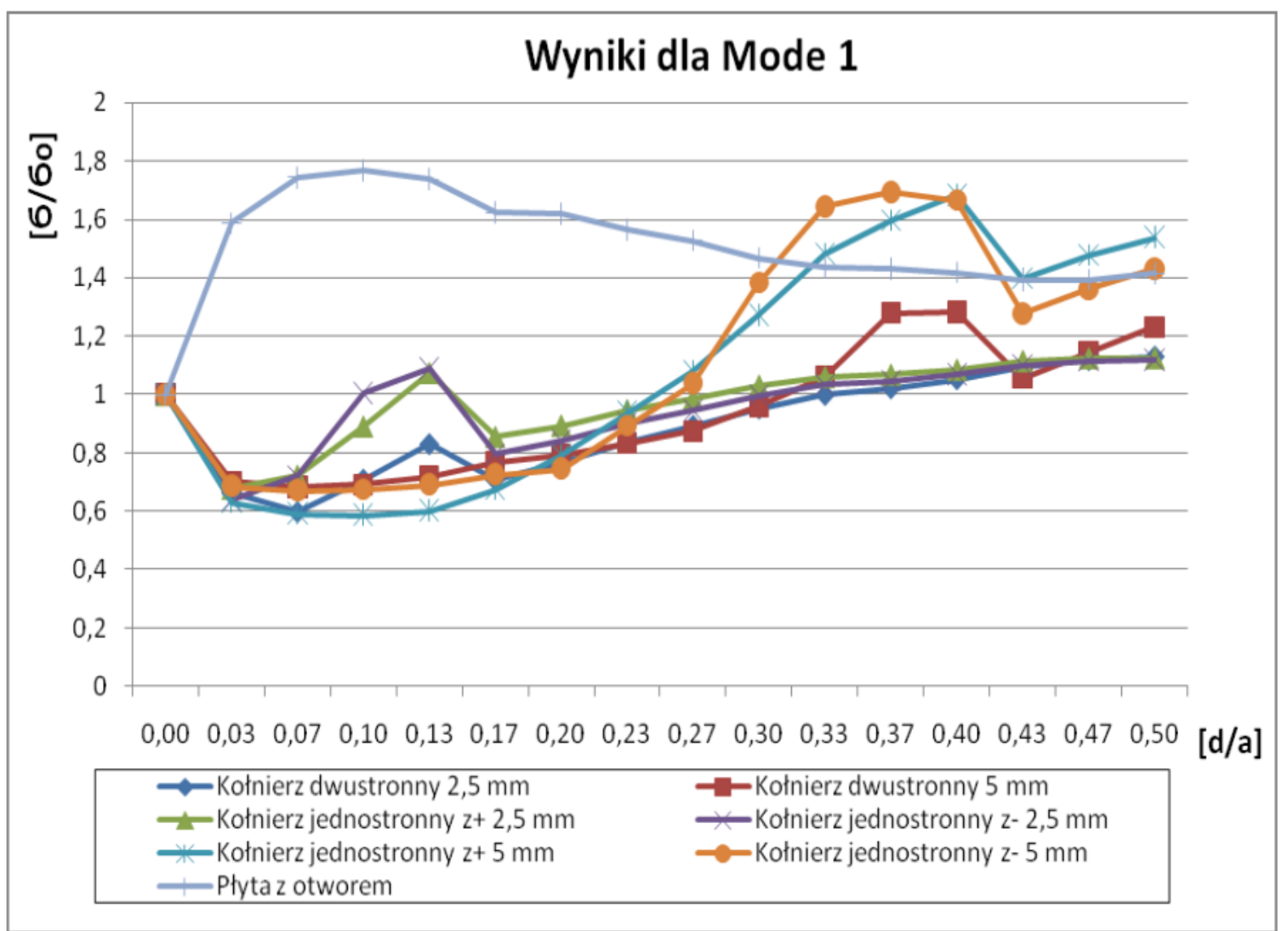



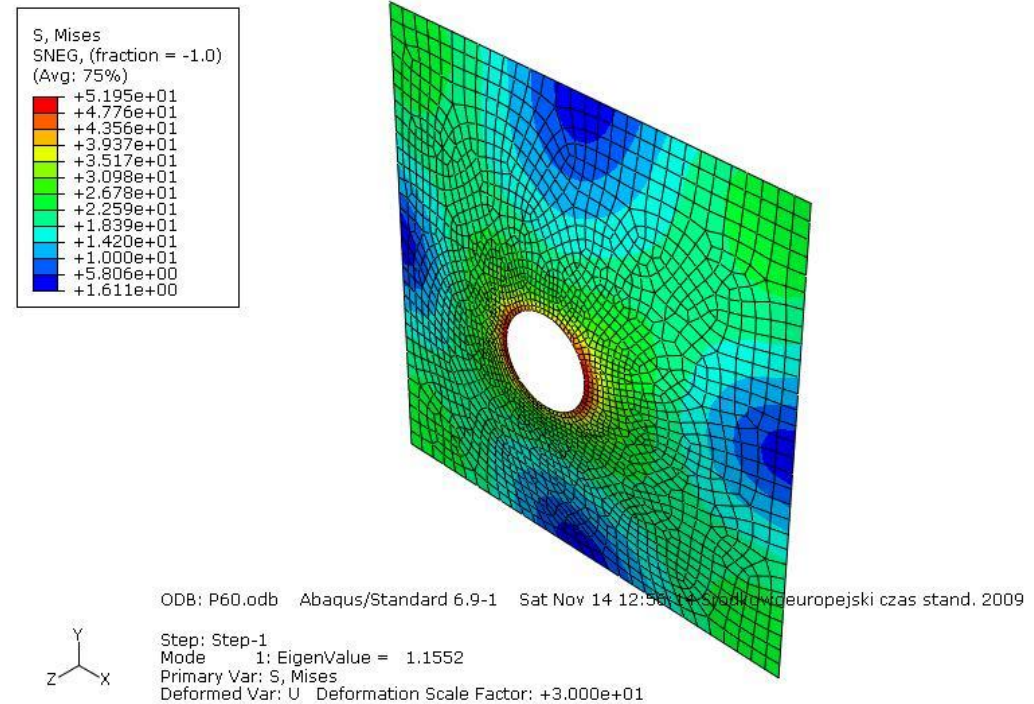

Rys. 2. Płyta $\mathrm{z}$ otworem $\mathrm{d}=60 \mathrm{~mm}$ (wersja 0 )
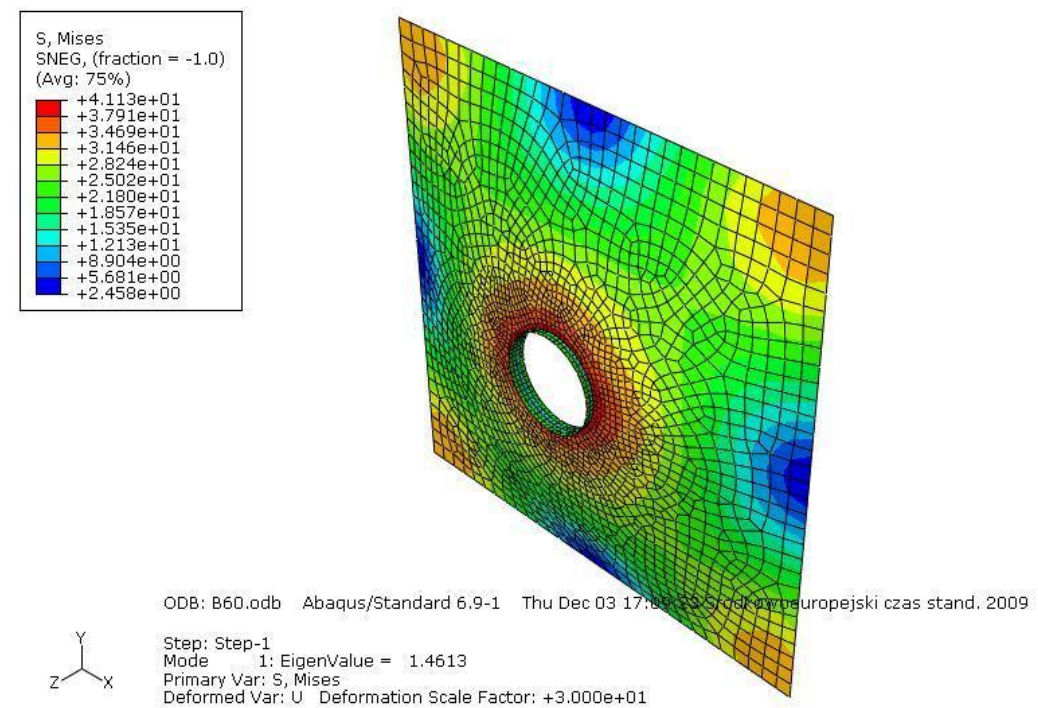

Rys. 3. Płyta $\mathrm{z}$ otworem $\mathrm{d}=60 \mathrm{~mm}$ (wersja B)
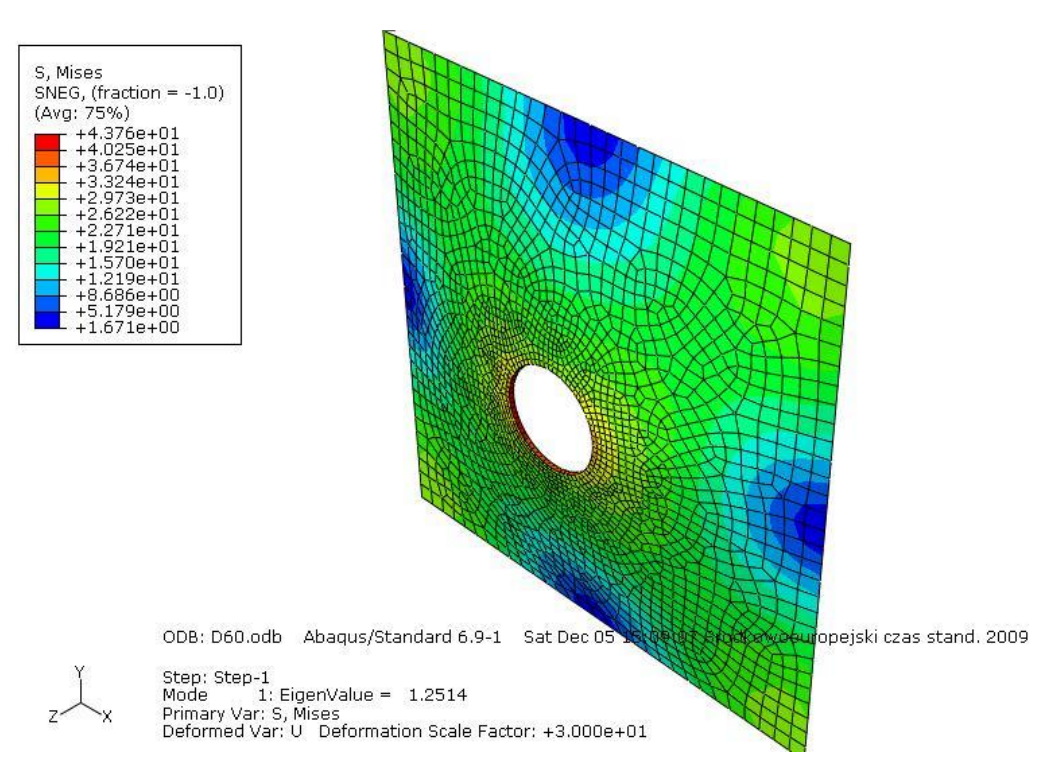

Rys. 4. Płyta $\mathrm{z}$ otworem $\mathrm{d}=60 \mathrm{~mm}$ (wersja D)
Rysunki 2 - 4 przedstawiają rozkład naprężeń zredukowanych dla trzech wybranych wariantów płyty $\mathrm{z}$ otworem $d=60 \mathrm{~mm}$.

\section{Zakończenie}

Badania potwierdzają, że wykonanie otworu w płycie pogarsza jej własności wytrzymałościowe. Ich zmiana nie przebiega jednak liniowo przez co dla rozpatrywanego modelu można wskazać najkorzystniejszą z punktu widzenia wytrzymałości średnicę otworu (d=130 mm). Jak już wspomniano na wstępie, wykonanie wycięcia w strukturze cienkościennej jest częstokroć konieczne, ale dzięki odpowiedniemu zakończeniu krawędzi otworu poprzez wykonanie kołnierza możliwa jest znaczna redukcja maksymalnych naprężeń zredukowanych (nawet o około $40 \%$ ) w stosunku do płyty z wycięciem bez kołnierza.

Wykres 1 przedstawia zmianę wartości maksymalnych naprężeń zredukowanych w zależności od średnicy kołowego wycięcia. Niezależnie od rozpatrywanego wariantu wykresy mają podobny przebieg. Charakteryzują się początkowo wzrostem naprężeń aż do osiagnięcia lokalnego maksimum. W tym zakresie naprężenia koncentrują się na krawędzi otworu (rysunek 3). Osiągnięcie ekstremów pokrywa się ze zmianą rozkładu naprężeń $\mathrm{w}$ elemencie. Następuje przeniesienie punktów koncentracji naprężeń na kołnierz oraz jednoczesne, zauważalne odciążenie samej płyty (rysunek 4). Po tej zmianie występuje charakterystyczne minimum, po którym następuje już tylko wzrost naprężeń. Występowanie dwóch ekstremów na wykresie jest bezpośrednio związane $\mathrm{z}$ wysokością ścianek kołnierza, im są wyższe tym później one następują. Nie jest natomiast związane $\mathrm{z}$ rodzajem oraz kierunkiem wyciagnięcia ścianek kołnierza. Od tych czynników zależą jednak wartości ekstremum, szczególnie korzystne są w przypadku kołnierzy dwustronnych, z technologicznego punktu widzenia trudniejszych do wykonania.

Dobrze zaprojektowany kołnierz powinien zapewnić rozkład naprężeń typowy dla zakresu po przekroczeniu lokalnego minimum. Koncentracja 
naprężeń występuje na kołnierzu, który nie jest bezpośrednio obciążony, natomiast bezpośrednio ściskana płyta będąca elementem nośnym jest wyraźnie odciążona. Maksymalne naprężenia płyty są nie tylko dużo niższe niż na kołnierzu oraz na krawędzi otworu bez wzmocnienia, ale także dla stosunkowo dużych średnic wycięcia (ponad 50\% długości boku) są one porównywalne do maksymalnych naprężeń płyty bez otworu.

W rozpatrywanych przypadkach zdecydowanie korzystniejsze okazały się niższe kołnierze zapewniające rozkład naprężeń po przekroczeniu lokalnego minimum. Opaska dwustronna w znacznym zakresie zapewnia najniższe naprężenia zredukowane, ale technologicznie jest trudna do wykonania. Kołnierze jednostronne nieznacznie im ustępuja, ale są $\mathrm{w}$ procesie obróbki plastycznej stosunkowo proste do wykonania w arkuszu blachy. Rozpatrując konkretny przypadek warto zwrócić uwage na kierunek wyciagnięcia ścianek kołnierza $(+\mathrm{z},-\mathrm{z})$, gdyż różnica wartości maksymalnych naprężeń zredukowanych może przekraczać $10 \%$.

\section{Literatura}

[1] Bazant Z. P. , Cedolin L., Stability of Structures, Dover Publication Inc., Mineola, New York 2003

[2] Eccher G., Rasmussen K. J. R., Zandonini R., Linear elastic isoparametric spline finie strap analysis of perforated thin-walled structures, Thin-Walled structures 46 (2008) 242-260

[3] El-Sawy M. K., Nazmy A. S., Effect fo aspect ratio on the elastic buckling of uniaxially loaded plates with eccentric holes, Thin-Walled Structures 39 (2001) 983-998

[4] El-Sawy M. K., Nazmy A. S., Ik bal Martini M., Elasto-plastic buckling of perforated plates under uniaxial compression, Thin-Walled Structures 42 (2004) 1083-1101
[5] El-Sawy M. K., Ik bal Martini M., Elastic stability of bi-axially loaded rectangular plates with a single circular hole, Thin-Walled Structures 45 (2007) 122-133

[6] Maiorana E., Pellegrino C., Modena C., Elastic stability of plates with circular and rectangular holes subjected to axial compression and bending moment, Thin-Walled Structures 47 (2009) 241-255

[7] Moen C. D., Schafer B.W., Elastic buckling of thin plates with holes in compression or bending, Thin-Walled Structures 47 (2009) 1597-1607

[8] Paik J. K., Ultimate strength of perforated steel plates under edge shear loading, Thin-Walled Structures 45 (2007) 301-306

[9] Paik J. K., Ultimate strength of perforated steel plates under combined biaxial compression and edge shear loads, Thin-Walled Structures 46 (2008) 207-213

[10] Pellegrino C., Maiorana E., Modena C., Linear and non-linear behaviour of steel plates with circular and rectangular holes under shear loading, Thin-Walled Structures 47 (2009) 607616

[11] Prabhakare D.L., Datta P.K., Vibration, Buckling and Parametric Instability Behaviour of Plates with Centrally Located Cutouts Subjected to In-Plane Edge Loading (Tension or Compression), Thin-Walled Structures 27 (1997) 287-310

[12] Shanmugam N.E., Openings in Thin-Walled Structures, Thin-Walled Structures 28 (1997) 355-372

[13] Shimizu S., Tension buckling of plate having a hole, Thin-Walled Structures 45 (2007) 827-833

[14] Timoshenko S., Woinowsky-Krieger S., Theory of plates and shells, McGraw-Hill Book Company 1987 